\title{
Victor Turner e antropologia da experiência
}

\author{
John C. Dawsey \\ Professor Livre-Docente do Departamento de \\ Antropologia da USP e coordenador do Núcleo \\ de Antropologia da Performance e do Drama \\ (Napedra/USP).
}

Em 1980, no encontro anual da American Anthropological Association, Victor Witter Turner, Edward Bruner e Barbara Myerhoff organizaram um simpósio sobre antropologia da experiência. Deste simpósio resultaria The Anthropology of Experience (1986), com o artigo, "Dewey, Dilthey, and Drama: An Essay in the Anthropology of Experience", de Turner (1986). ${ }^{1}$ Trata-se de um dos seus últimos textos. Publicado três anos após a morte do seu autor - e no mesmo ano da publicaçáo de alguns dos escritos mais conhecidos da antropologia "pósmoderna" ${ }^{-}$, o subtítulo poderia evocar, para um leitor desavisado, a imagem de um testamento com os conselhos de um velho antropólogo, do alto da sua "experiência", alertando os mais novos para riscos iminentes. Certamente não é essa a idéia que Turner tem de experiência.

Se no ensaio de Turner algum conselho houver, certamente ele não seria $\mathrm{da}$ ordem de "não corram riscos", ou "evitem perigos". A etimologia de experiência, ressalta o autor, deriva do indo-europeu per, com o significado literal,

1. Também em 1980, ao discutir os usos da metáfora do drama nas ciências sociais, Clifford Geertz ([1980] 1983:29) destaca o conceito de experiência como sendo uma categoria central para o entendimento da contribuiçáo de Victor Turner ao campo da antropologia.

2. Aqui me refiro a Writing Culture: The Poetics and Politics of Ethnography (Clifford e Marcus 1986) e Anthropology as Cultural Critique: An Experimental Moment in the Human Sciences (Marcus e Fischer 1986). justamente, de "tentar, aventurar-se, correr riscos". Experiência e perigo vêm da mesma raiz. A derivação grega, perao, "passar por", também chama a atenção de Turner pelo modo como evoca a idéia de ritos de passagem.

A idéia de passagem náo deixa de ser sugestiva. De novo, retomando o início do parágrafo anterior, se nesse ensaio algum conselho houver, é provável que ele seja da espécie que Benjamin descobriu na atividade do narrador: uma sugestáo de como continuar uma história (Benjamin 1985b: 200). Porém, não se trata de testamento. Mais se parece com um manifesto. Um detalhe: nascido em 1920, Turner não era táo velho assim quando escreveu este texto.

Num momento de inflexáo no campo da antropologia, três imagens do passado articulam-se ao presente, inscrevendo-se no título de um ensaio: Dewey, Dilthey e drama. A terceira imagem náo deixa de evocar o jovem Turner e suas reflexôes originárias, saídos do redemoinho dos anos de 1950, quando ele iniciava-se nas pesquisas de campo.

A figura de Dilthey também aparece com destaque na introdução de From Ritual to Theatre: The Human Seriousness of Play, na qual uma premissa se anuncia: a antropologia da performance é uma parte essencial da antropologia da experiência (Turner 1982b: 13). Através do processo de performance, o contido ou suprimido revela-se - Dilthey usa o termo Ausdruck, de ausdrucken, "espremer". Citando 
Dilthey, Turner descreve cinco "momentos" que constituem a estrutura processual de cada erlebnis, ou experiência vivida: 1) algo acontece ao nível da percepçáo (sendo que a dor ou o prazer podem ser sentidos de forma mais intensa do que comportamentos repetitivos ou de rotina); 2) imagens de experiências do passado são evocadas e delineadas - de forma aguda; 3) emoçóes associadas aos eventos do passado são revividas; 4) o passado articula-se ao presente numa "relação musical" (conforme a analogia de Dilthey), tornando possível a descoberta e construção de significado; e 5) a experiência se completa através de uma forma de "expressão". Performance - termo que deriva do francês antigo parfournir, "completar" ou "realizar inteiramente" - refere-se, justamente, ao momento da expressão. A performance completa uma experiência (Turner 1982b: 13-14).

A imagem de Dilthey também fulgura em "The anthropology of performance" (Turner 1987b). O próprio Turner apresenta-se neste artigo como um dos precursores da "virada pós-moderna" na antropologia. O "perigo", diz Turner, não vem dos chamados "pós-modernos", mas das tentativas "clássicas" e recentes de fazer da antropologia uma das variantes das ciências naturais, uma ciência do ser humano sem vida, despojada de experiência vivida - mais um sintoma de uma época em que "o significado é que não há significado" ${ }^{3}$ Daí a importância de Dilthey. No mundo contemporâneo a busca do sentido torna-se cada vez mais difícil. As afinidades entre a antropologia "pós-moderna" e antropologia da experiência (e da performance) de Turner revelam-se num "desvio": a atenção do antropólogo volta-se aos ruídos e elementos estruturalmente arredios.

Nesta apresentação, levando a sério "a seriedade humana da brincadeira" [The Human

3. Este comentário, sobre uma época em que "o significado é que não há significado”, aparece em Turner (1986: 43).
Seriousness of Play] (Turner 1982a), eu gostaria de "brincar" com o modelo de "drama social" do autor, explorando uma possível meta-narrativa de Dewey, Dilthey and Drama: An Essay in the Anthropology of Experience. Embora eu náo esteja exatamente contribuindo para atenuar algumas das críticas aos usos da noção de drama social - que vira, de acordo com Geertz, "uma fórmula para todas as estaçóes" (Geertz [1980] 1983: 28) -, intriga-me ver como o próprio texto de Turner ilumina uma forma dramática. Alguns ruídos que surgem, quem sabe, do limen do seu ensaio podem suscitar questóes em relação à noção de experiência. Haveria em Turner a nostalgia por uma experiência que se expressa melhor na noção de erfahrung do que na de erlebnis? Afinidades entre a antropologia de Turner e o pensamento benjaminiano merecem atenção. Assim como algumas diferenças. Antes de tudo isso, porém, convido o leitor a um exercício de rememoraçáo do percurso de Turner, que vai, como veremos, do ritual ao teatro, e do liminar ao liminoide.

\section{Ritos e dramas sociais}

À primeira vista, o percurso de Turner sugere algo como um esquema evolucionista: do ritual ao teatro. No princípio, o ritual. Por outro lado, questóes do pensamento teatral colocamse desde o início. Inclusive, a mãe de Turner, Violet Witter, que era atriz, foi uma das fundadoras do Teatro Nacional Escocês nos anos de 1920. Em Schism and Continuity in an African Society, Turner supóe que ritos de passagem, assim como dramas sociais, evocam uma forma estética que se encontra na tragédia grega (Turner [1957] 1996). As atençóes de Turner para elementos estruturalmente arredios evidenciam-se desde suas primeiras pesquisas, à luz das discussões de Max Gluckman sobre "ritos de rebeliāo" (Gluckman 1954), de Van Gen- 
nep sobre "ritos de passagem" ([1908] 1960), e, certamente, de Violet Witter sobre teatro.

Roland Barthes define teatro como uma atividade que "calcula o lugar olhado das coisas" (Barthes 1990: 85). Essa idéia pode ser interessante para se discutir a própria antropologia, particularmente como ela se manifesta em Victor Turner. As afinidades entre procedimentos etnográficos e ritos de passagem são bastante conhecidas. Ambos envolvem estratégias que visam produzir efeitos de estranhamento em relaçáo ao familiar. A partir de deslocamentos do lugar olhado das coisas, conhecimento é produzido e adquire densidade. A sacada de Turner foi ver como as próprias sociedades sacaneiam-se a si mesmas, brincando com o perigo, e suscitando efeitos de paralisia em relação ao fluxo da vida cotidiana. Isso através de ritos, cultos, festas, carnavais, música, dança, teatro, procissóes, rebelióes e outras formas expressivas. Universos sociais e simbólicos se recriam a partir de elementos do caos.

Nos anos de 1950, vendo como as aldeias Ndembu ganhavam vida em momentos de crise, Victor Turner elaborou o modelo de drama social que lhe serviria como instrumento de análise, inclusive nas formulaçóes posteriores da antropologia da performance e antropologia da experiência. Discussóes sobre ritos de passagem foram fundamentais para as formulaçóes de Turner. De acordo com o modelo de Van Gennep, ritos de passagem envolvem três "momentos”, ou sub-ritos: 1) de separação, 2) de transição ("liminares"), e 3) de reagregação. No modelo de drama social elaborado por Turner, os três momentos desdobram-se em quatro: 1) ruptura, 2) crise e intensificação da crise, 3) ação reparadora, e 4) desfecho (que pode levar à harmonia ou cisão social).

Estruturas sociais - entendidas, sob o signo da antropologia social britânica, como conjuntos de relaçóes sociais empiricamente observáveis - estão carregadas de tensóes. Em determinados instantes, tensóes afloram. Elementos náo resolvidos da vida social se manifestam. Irrompem substratos mais fundos do universo social e simbólico. As relaçóes sociais iluminam-se a partir de fontes de luz subterrâneas.

Victor Turner produz um desvio metodológico no campo da antropologia social britânica. Para se entender uma estrutura, é preciso suscitar um desvio. Busca-se um lugar de onde seja possível detectar os elementos náo-óbvios das relaçóes sociais. Estruturas sociais revelam-se com intensidade maior em momentos extraordinários, que se configuram como manifestaçóes de "anti-estrutura". O antropólogo procura acompanhar os movimentos surpreendentes da vida social.

Experiências que irrompem em tempos e espaços liminares podem ser fundantes. Dramas sociais propiciam experiências primárias. ${ }^{4}$ Fenômenos suprimidos vêm à superfície. Elementos residuais da história articulam-se ao presente. Abrem-se possibilidades de comunicação com estratos inferiores, mais fundos e amplos da vida social. Estruturas decompóemse - às vezes, com efeitos lúdicos. $\mathrm{O}$ riso faz estremecer as duras superfícies da vida social. Fragmentos distantes uns dos outros entram em relaçóes inesperadas e reveladoras, como montagens. Figuras grotescas manifestam-se em meio a experiências carnavalizantes (Turner 1967b: 105-106). No espelho mágico de uma experiência liminar, a sociedade pode ver-se a si mesma a partir de múltiplos ângulos, experimentando, num estado de subjuntividade, com as formas alteradas do ser. ${ }^{5}$

No espelho da anti-estrutura, figuras vistas como estruturalmente poderosas podem

4. Turner discute a noção de "processo primário", termo sugerido por Dario Zadra, em seu artigo sobre Hidalgo e a revolução mexicana (Turner 1974a: 110).

5. A metáfora do "espelho mágico" aparece em vários escritos de Victor Turner (Turner 1987a: 22). 
mostrar-se como sendo extremamente frágeis. Inversamente, personagens estruturalmente frágeis transformam-se em seres de extraordinário poder (Turner 1969b: 94-130). De fontes liminares, imagens e criaturas ctônicas irrompem com poderes de cura para revitalizar tecidos sociais. ${ }^{6}$ Entidades ambíguas ou anômalas, consideradas como sendo estruturalmente perigosas, energizam circuitos de comunicação atrofiados. ${ }^{7}$ Abrem-se passagens em sistemas classificatórios estáticos. Surgem áreas de contágio. Espaços híbridos. Escândalos lógicos.

Nos momentos de suspensão das relaçóes cotidianas é possível ter uma percepção mais funda dos laços que unem as pessoas. Despojadas dos sinais diacríticos que as diferenciam e as contrapóem no tecido social, e sob os efeitos de choque que acompanham o curto-circuito desses sinais numa situação de liminaridade, pessoas podem ver-se frente a frente. Sem mediaçôes. Voltam a sentir-se como havendo sido feitas do mesmo barro do qual o universo social e simbólico, como se movido pela ação de alguma oleira oculta, recria-se. A essa experiência Turner dá o nome de communitas. ${ }^{8}$

Da experiência no límen, propiciada por dramas sociais, surgem poderosos símbolos

6. O terceiro momento dos dramas sociais, referente à reparação de crises, é propício, de acordo com Turner, para a manifestação de ritos de cura (Turner 1968; 1967a: 359-393).

7. A discussão de Mary Douglas sobre o pangolim em rituais da cultura lele oferece um exemplo desse fenômeno (Douglas [1966] 1976: 202-204).

8. Turner encontra nas discussôes de Durkheim sobre "efervescência social" um exemplo de liminaridade e communitas (Durkheim [1912] 1989: 456). Communitas, termo inspirado pelas reflexóes de Martin Buber, não deve ser confundido com qualquer princípio de organização social em comunidade, ou com formas de solidariedade descritas por Durkheim. Trata-se de uma experiência que irrompe de modo espontâneo a partir de momentos de interrupção das formas de organização social (Turner 1969b: 126127). multivocais. ${ }^{9}$ Assim se articulam diferenças. Os fios que tecem as redes de significado unificamse em tramas carregadas de tensóes.

\section{Do liminar ao liminoide}

A publicação de From Ritual to Theatre: The Human Seriousness of Play, em 1982, marca uma inflexão no pensamento de Victor Turner. Aqui se encontram as suas primeiras formulaçóes sobre uma antropologia da performance, um campo de estudos que surge nas interfaces da antropologia e do teatro nos anos de 1970, a partir do encontro e colaboração entre Victor Turner e Richard Schechner. Uma de suas afirmaçóes é particularmente reveladora. Até aqui as ciências sociais praticamente só têm se preocupado com questóes de estrutura e desempenho de papéis, diz Turner. A sua própria abordagem, ele prossegue, procura focar os momentos de interrupção de papéis (Turner 1982c: 46).

Esta questão é retomada em "The Anthropology of Performance", onde Turner aponta as diferenças entre a abordagem de Erving Goffman e a sua. ${ }^{10}$ Ao passo que Goffman apresenta-se como um observador do teatro da vida cotidiana, Turner se interessa particularmente pelos momentos de suspensão de papéis, ou seja, pelo meta-teatro da vida social. ${ }^{11}$

Em "Liminal to liminoid, in Play, Flow, Ritual: An Essay in Comparative Symbology”, Turner procura comparar sistemas simbólicos de culturas que se desenvolveram antes e depois

9. Dois artigos de Turner discutem a polifonia dos símbolos e o modo como eles surgem ou são elaborados em meio aos dramas sociais (Turner 1974a: 98-155; 1974c: 60-97).

10. De Goffman, ver, especialmente, The Presentation of Self in Everyday Life (1959).

11. Turner diz: "se a vida cotidiana pode ser consideradea como uma espécie de teatro, o drama social pode ser visto como meta-teatro...” (Turner 1987b: 76; minha tradução). 
da revoluçáo industrial (Turner 1982c:30). A palavra liminoid, inventada por Turner, apresenta a terminação oid, derivada do grego eidos que designa "forma" e sinaliza "semelhança". Liminoid, portanto, é semelhante sem ser idêntico ao liminar.

As idéias sobre gêneros liminoides de ação simbólica haviam sido anunciadas, embora não elaboradas, no prefácio de Dramas, Fields and Metaphors: Symbolic Action in Human Society, indicando a direção de suas pesquisas posteriores:

Eu gostaria de sugerir a idéia de que aquilo que temos tratado como sendo os gêneros "sérios" de ação simbólica - ritual, mito, tragédia, e comédia (no seu "nascimento") - estáo profundamente implicados em visões repetitivas do processo social, ao passo que os gêneros que floresceram desde a Revolução Industrial (as artes e ciências modernas), embora menos sérios aos olhos da população em geral (ciência pura, entretenimento, interesses da elite), têm apresentado um potencial maior para transformar os modos como as pessoas se relacionam entre elas e o conteúdo de suas relaçóes. Sua influência tem sido mais insidiosa. Tendo-se em vista o fato de se manifestarem em espaços exteriores às arenas centrais da produção industrial, e de se constituírem analogamente como "liminoides" em relação aos processos e fenômenos liminares de sociedades tribais e agrárias, a sua própria exterioridade as libera da atividade funcional em relação ao pensamento e comportamento dos membros da sociedade. Constituem para os seus agentes e audiências uma atividade optativa - a ausência de obrigaçóes ou constrangimentos advindos de normas externas lhes confere uma qualidade prazerosa que favorece a sua absorção nas consciências individuais. Desta forma, o prazer transforma-se em assunto sério no contexto de mudanças inovadoras (Turner 1974b:16; minha tradução).
Nas culturas pré-industriais, esferas de atividade ritual não se separam do trabalho: ritual é trabalho. E trabalho não se desvincula $\mathrm{da}$ vida lúdica da coletividade. Nessas sociedades, particularmente, a brincadeira constitui um dos componentes centrais dos processos de revitalização de estruturas existentes. $\mathrm{O}$ espelho mágico dos rituais propicia uma poderosa experiência coletiva.

Sociedades industrializadas produzem o que poderíamos chamar de um descentramento e fragmentação da atividade de recriação de universos simbólicos. Esferas do trabalho ganham autonomia. Como instância complementar ao trabalho, surge a esfera do lazer - que não deixa de se constituir como um setor do mercado. Processos liminares de produção simbólica perdem poder na medida em que, simultaneamente, geram e cedem espaço a múltiplos gêneros de entretenimento. As formas de expressão simbólica se dispersam, num movimento de diáspora, acompanhando a fragmentação das relaçóes sociais. $\mathrm{O}$ espelho mágico dos rituais se parte. Em lugar de um espelhão mágico, poderíamos dizer, surge uma multiplicidade de fragmentos e estilhaços de espelhos, com efeitos caleidoscópicos, produzindo uma imensa variedade de cambiantes, irrequietas e luminosas imagens. ${ }^{12}$

As diferenças e semelhanças sinalizadas por Turner em sua análise exploratória dos fenômenos liminares e liminoides são resumidas a seguir:

1) Fenômenos liminares tendem a predominar em sociedades tribais ou agrárias, caracterizando-se por princípios que Durkheim chamou de "solidariedade mecânica". Fenômenos liminoides ganham destaque em sociedades de "solidariedade orgânica", em meio aos desdobramentos da Revolução Industrial.

12. Cf. nota 5 , para uma referência do uso da metáfora do "espelho mágico" em Turner. A metáfora do estilhaçamento de um "espelhão mágico" é inferida de suas discussões. 
2) Fenômenos liminares tendem a emergir de uma experiência coletiva, associando-se a ritmos cíclicos, biológicos e sócio-estruturais, ou com crises que ocorrem nesses processos. Fenômenos liminoides geralmente apresentam-se como produtos individuais, embora os seus efeitos freqüentemente sejam coletivos ou de "massa".

3) Fenômenos liminares integram-se centralmente ao processo social total, constituindo o pólo negativo, subjuntivo e anti-estrutural de um todo que se constitui de modo dialético. Fenômenos liminoides desenvolvem-se às margens dos processos centrais da economia e política. Trata-se de manifestaçóes plurais, fragmentárias, e experimentais que ocorrem nas interfaces e interstícios do conjunto de instituições centrais.

4) Fenômenos liminares tendem a apresentar características semelhantes às que se encontram nas discussóes de Durkheim sobre "representaçóes coletivas". Trata-se da produção de símbolos que evocam significados intelectuais e emotivos comuns a todos os membros do grupo. Embora se manifestem freqüentemente como a antítese das representaçóes coletivas "profanas", não deixam de compartilhar das suas feiçóes coletivas. Fenômenos liminoides tendem a apresentar características mais idiossincráticas, associando-se a indivíduos e grupos específicos que freqüentemente competem num mercado do lazer, ou de bens simbólicos. Nesse caso, as dimensóes "pessoais e psicológicas" dos símbolos têm preponderância sobre as dimensôes "objetivas e sociais".

5) Fenômenos liminares, mesmo quando produzem efeitos de inversão, tendem a revitalizar estruturas sociais e contribuir para o bom funcionamento dos sistemas, reduzindo ruídos e tensóes. Fenômenos liminoides, por outro lado, freqüentemente surgem como manifestaçóes de crítica social que, em determinadas condiçóes, podem suscitar transformaçóes com desdobramentos revolucionários (Turner 1982c: 53-55).

\section{O drama de "Dewey, Dilthey, and Drama..."}

Agora, passemos ao ensaio que serve como pré-texto desta apresentação. Invocando o espírito liminoide que, de acordo com Turner, caracteriza boa parte da atividade intelectual no mundo contemporâneo, como também a "seriedade humana da brincadeira" (que talvez a caracterize um pouco menos) - sou tentado, como já falei no início desta apresentação, a brincar com o modelo de drama social do autor, aplicando-o ao próprio "Dewey, Dilthey, and Drama: An Essay in the Anthropology of Experience". O artigo, de fato, apresenta elementos de um drama, que podem ser pensados em termos dos momentos de "ruptura", "crise e intensificação da crise", "ação reparadora" e "desfecho". No drama do artigo - e aqui é preciso atenção - a própria metáfora do drama social de Turner aparece como momento importante de "reparação" da crise, junto às contribuiçốes de Dilthey e Dewey. $\mathrm{O}$ elemento de "ruptura" pode ser identificado com a Revolução Industrial. E a "crise e intensificação da crise" com as dificuldades encontradas para ressignificar o mundo. Trata-se de uma "crise de ação simbólica". O indivíduo carrega a responsabilidade de dar sentido ao seu universo. Os gêneros expressivos foram desmembrados e perderam poder no mundo contemporâneo. Foram colocados às margens dos processos sociais centrais. As noçôes de drama social e liminaridade (e suas fontes de poder) são importantes para se buscar um desfecho "feliz". Este vem com uma discussão sobre a experiência de communitas suscitada pelo teatro!

Tomando os quatros momentos do "drama social" como elementos meta-narrativos 
(codificados “a”, "b”, “c”, e “d”), as seqüências do ensaio de Turner podem ser analisadas da seguinte forma:

\section{[C1] AÇÃO REPARADORA: DEWEY.} Inicia-se com uma discussão de Dewey, autor estratégico por sua ênfase na articulação das tradiçóes do passado ao presente (o tempo do “agora”). Tradição não precisa (nem deve?) virar sacrifício. Assim como a tradição, a expressão artística não se desvincula do cotidiano. Tratase de uma "celebração da experiência cotidiana (ordinary experience)". Dewey aparece, no contexto do ensaio, como um dos atores centrais que contribuem para uma "ação reparadora" da "crise" de fundo, ainda a ser delineada. Porém, Turner irá propor algumas reformulaçóes em relação à sua noção de experiência.

\section{[C2] AÇÃO REPARADORA: DILTHEY.} A primeira reformulação vem de Dilthey, que propicia uma distinção fundamental entre "mera experiência” e "uma experiência”. Aqui se introduz a noção de erlebnis, experiência vivida. A etimologia de experiência remete à noção de "perigo", etc. Os elementos do modelo de experiência discutidos na introdução de From Ritual to Theatre aparecem, embora não de modo esquemático. Dilthey surge como uma poderosa figura ancestral, tal como as que irrompem durante ritos de cura entre os Ndembu. ${ }^{13}$

[B] CRISE E INTENSIFICAÇÃO DA CRISE: DIFICULDADE LIMINOIDE DE SIGNIFICAR O MUNDO. Surgem as pri-

13. Como já foi visto, Dilthey é uma figura recorrente nos artigos de Turner. Na introdução de From Ritual to Theatre: The Human Seriousness of Play, Turner imagina a frase "O Professor Dilthey aprovaria" como um selo final de aprovação das tentativas de gerarse uma antropologia e um teatro da experiência (Cf. Turner 1982b: 18). meiras referências ao que se poderia ver, nos termos do modelo de "drama social", como "a crise e intensificação da crise". Turner discute as dificuldades de se recriar universos sociais e simbólicos no mundo contemporâneo, onde indivíduos se vêem sozinhos e abandonados diante da responsabilidade de darem sentido às suas vidas. Trata-se de uma "crise de ação simbólica”. Como essa discussão segue à apresentação da noção de erlebnis, seria possível perguntar se Turner náo estaria se vendo diante dos limites dessa idéia de experiência.

[C3] AÇÃO REPARADORA: A METÁFORA DO “DRAMA SOCIAL” DE TURNER. Turner parece sinalizar algo nessa direção: a unidade de experiência de Dilthey privilegia questóes de cultura e psicologia. Talvez a menção à psicologia seja crucial. Em "Liminal to liminoid..." Turner observa que símbolos liminoides tendem a ser de natureza "pessoal e psicológica” em vez de “objetiva e social”. Até que ponto erlebnis se restringe à experiência vivida do indivíduo? O artigo de Roger D. Abrahams, que segue ao de Turner em The Anthropology of Experience, é bastante explícito nesse sentido (Abrahams 1986: 45-72). Abrahams sugere cautela nos usos da noção de "experiência", produzindo um distanciamento reflexivo em relação ao entusiasmo demonstrado por ela ao longo da história cultural dos Estados Unidos. De qualquer forma, num movimento que revela o caráter propositivo de seu ensaio, Turner procura demonstrar a relevância de sua noção de "drama social" para questóes de "experiência”. Dramas sociais podem propiciar formas de acesso a substratos do universo social e simbólico. Ritos que surgem como expressóes de "ação reparadora" (terceiro momento do drama social), assim como ritos que inauguram momentos de "ruptura" (primeiro), criam o "palco" para que estruturas de experiência únicas (erlebnis) possam ocorrer. Isso devido às fontes 
de poder (e perigo) que se associam ao límen. Enfim, a própria noção de "drama social”, em conjunto com as idéias de Dilthey e Dewey, apresenta-se, na organização do artigo, como elemento crucial para a "reparação da crise".

\section{[A] RUPTURA: REVOLUÇÃO INDUS-} TRIAL; e [B] CRISE E INTENSIFICAÇÃO DA CRISE: DIFICULDADE LIMINOIDE DE SIGNIFICAR O MUNDO. Turner observa: "os rápidos avanços na escala e complexidade da sociedade, particularmente após a industrialização, fizeram passar essa configuração liminar unificada pelo prisma da divisão do trabalho (...) reduzindo cada um dos seus domínios sensoriais a um conjunto de gêneros de entretenimento que florescem no tempo de lazer da sociedade, não mais no lugar central de controle" (Turner 1986: 42). Sinaliza-se nesse trecho, com a menção à industrialização, aquilo que pode ser entendido como o primeiro momento do "drama social": a "ruptura". A seguir, o autor evoca processos associados ao que podemos interpretar como a "crise e intensificação da crise", referindo-se aos "gêneros especializados amputados" que surgem do "desmembramento" (sparagmos) das formas de ação simbólica. Mas Turner também sugere perspectivas para um desfecho "feliz": em meio à fragmentação dos gêneros, há sinais de uma busca para recuperar dimensôes suprimidas da experiência do "numinoso", característica do "ritual arcaico".

\section{[C1] e [C3]. AÇÃO REPARADORA:} DEWEY E DRAMA SOCIAL. A seguir, Turner retoma a discussão de Dewey - de que "a forma estética do teatro é inerente à própria vida sociocultural". Mas, interpreta Dewey à luz da noção de "drama social". A natureza terapêutica e reflexiva do teatro tem suas fontes na liminaridade. Trata-se de uma unificação de posiçóes (as de Turner e Dewey, inicialmente distintas) para a "açáo reparadora".
[D] DESFECHO: COMMUNITAS. Enfim, o desfecho. As idéias de Dewey, complementadas por investigaçóes na neurobiologia, contribuem para mostrar que o teatro e outros gêneros de performance podem suscitar experiências de communitas. "Um senso de harmonia com o universo se evidencia e o planeta inteiro é sentido como uma communitas" (Turner 1986: 43). Pouco antes de chegar a esse momento climático, Turner comenta que o ritual e as artes performativas derivam do cerne ("coraçâo") liminar do drama social - até mesmo, como acontece freqüentemente em "culturas declinantes", em que "o significado é de que não há significado". Completou-se um percurso. Da "celebração da experiência cotidiana (ordinary experience)" de Dewey chegou-se, em companhia do próprio Dewey, à experiência extraordinária que interrompe o cotidiano, dando-lhe sentido. E, sob a inspiração de Dilthey, o grande espírito protetor ancestral, foi-se da "mera experiência" a "uma experiência".

Enfim, esse exercício de interpretaçáo da meta-narrativa "dramática" do texto de Turner sugere um forma:

\begin{tabular}{|l|l|l|}
\hline Frase inicial & Título & Dewey, Dilthey, e drama \\
\hline C1 & Ação reparadora & Dewey \\
\hline C2 & Ação reparadora & Dilthey \\
\hline B & Crise... & Dificuldade liminoide... \\
\hline C3 & Ação reparadora & Drama (Turner) \\
\hline A & Ruptura & Revolução industrial \\
\hline B & Crise... & Dificuldade liminoide \\
\hline C1 e C3 & Ação reparadora & Dewey e drama (Turner) \\
\hline D & Desfecho & $\begin{array}{l}\text { Communitas } \\
\text { (Dewey, Dilthey e drama) }\end{array}$ \\
\hline
\end{tabular}

Esta codificação poderá evocar "as partes de uma peça musical - que são repetidas, variadas, combinadas, e retomadas". ${ }^{14}$ A analogia é propícia. Conforme o modelo de experiência de

14. Agradeço ao meu orientando, André-Kees de Moraes Schouten, mestrando do Programa de Pós-Graduação em Antropologia Social da USP, por esta observaçáo. 
Dilthey, citado no início desta apresentação, a descoberta e construçáo do significado tornamse possíveis na medida em que o passado articula-se ao presente numa "relação musical". $\mathrm{Na}$ frase inicial do título irrompem três imagens do passado: Dewey, Dilthey, e... o jovem Turner (que elaborou o modelo do drama social). Estas, poderíamos sugerir, articulam-se a um presente que é vivido como uma "crise": a dificuldade liminoide de ressignificar o mundo. ${ }^{15}$ No caso de Dewey e Dilthey, particularmente, trata-se de vozes "ancestrais" oriundas de substratos mais próximos aos de onde ocorrem os abalos originários da "ruptura", a Revolução Industrial. No desfecho, ressoam novamente Dewey, Dilthey e drama - agora em voz uníssona. Até mesmo alguns ruídos evocativos da "crise" retornam neste final. Vamos a eles.

\section{Ruídos}

Um "final feliz": podemos ter experiências de communitas no teatro. Porém, o desfecho do artigo - como revela a frase de Turner sobre "culturas declinantes" - não elimina os ruídos. Seria surpreendente para o próprio Turner, particularmente, se os eliminasse: desfechos harmonizantes (ou até unissonantes) tendem a oferecer apenas soluçóes parciais e provisórias. Mesmo sem recorrer a Bertolt Brecht, Antonin Artaud, Nelson Rodrigues, José Celso Martinez Corrêa ou outras expressóes do teatro contemporâneo, há no próprio texto de Turner - imagino no seu límen, em meio a inúmeras "sugestôes de como continuar a história” - razóes para estranhar-se o desfecho. Se há nos escritos de Turner uma espécie de nostalgia por experiências de communitas,

15. Observa-se que o ensaio foi publicado, como vimos anteriormente, no mesmo ano em que ganha força, no campo da antropologia, a percepçáo de uma "crise das representaçôes" - através da publicação de dois dos textos mais conhecidos da antropologia "pós-moderna”. Cf. nota no. 2 . também lá se encontram bons indícios de cautela em relação às suas manifestaçôes. Ressalta-se nesse autor, além da busca por communitas, a sua atenção aos ruídos. Um lembrete: aquilo que interessa a Turner é o que ele chama de "communitas espontânea”, e não as manifestaçóes superficiais, discutidas no capítulo quatro de The Ritual Process, como "communitas ideológica" e "communitas normativa" (Turner 1969a: 131165).

Hoje temos acesso a experiências liminoides, cujas origens remetem às dimensóes do liminar, diz Turner. Até que ponto é possível num mundo pós-revolução industrial o acesso direto a experiências liminares não está claro. No final de "Liminal to liminoid..." Turner parece buscar na noção de flow (fluxo) de Csikszentmihalyi - noçáo que se refere ao envolvimento total da pessoa naquilo que ela faz - algo parecido com a communitas (Csikszentmihalyi 1990). O desfecho daquele artigo - em contraste com "Dewey, Dilthey and drama..." - é anti-climático: communitas é algo que se manifesta entre indivíduos, enquanto flow acontece no indivíduo. Flow pertence ao domínio da estrutura.

Duas questôes se oferecem:

1. A nostalgia de Turner pela experiência liminar que os rituais em sociedades de solidariedade mecânica podem proporcionar teria a ver com uma percepção aguda, embora não explicitada, dos limites da noção de erlebnis, experiência vivida? Creio que a tentativa de articular a noção de dramas sociais à discussão sobre erlebnis sugere que sim.

2. Rondando esse ensaio - no seu limen, quem sabe - não haveria outra categoria de experiência discutida por Dilthey - erfahrung? Não seria esta categoria mais apropriada do que a de erlebnis para iluminar a nostalgia de Turner por uma experiência coletiva, vivida em comum, passada de geração em geração, e capaz de recriar um universo social e simbólico pleno de significado? 


\section{Benjaminianas}

As afinidades entre as visōes de Victor Turner a respeito de fenômenos e processos liminares, e a de Benjamin sobre erfahrung chamam atenção. Ambas evocam a idéia de passagem. "Lembremos aqui", diz Gagnebin, "que a palavra Erfahrung vem do radical fahr - usado ainda no antigo alemáo no seu sentido literal de percorrer, de atravessar uma regiáo durante uma viagem" (Gagnebin 1994: 66).

Experiência, no sentido de erfahrung, forma-se através da associaçáo de dois saberes: da pessoa que vem de longe, vista como quem tem muito que contar; e da pessoa que passou a vida "sem sair do seu país e que conhece suas histórias e tradições”. Benjamin escreve:

Se quisermos concretizar esses dois grupos através dos seus representantes arcaicos, podemos dizer que um é exemplificado pelo camponês sedentário, e outro pelo marinheiro comerciante. (...) A extensão real do reino narrativo, em todo o seu alcance histórico, só pode ser compreendido se levarmos em conta a interpenetração desses dois tipos arcaicos. $\mathrm{O}$ sistema corporativo medieval contribuiu especialmente para essa interpenetração. $\mathrm{O}$ mestre sedentário e os aprendizes migrantes trabalhavam juntos na mesma oficina; cada mestre tinha sido um aprendiz ambulante antes de se fixar em sua pátria ou no estrangeiro. (...) No sistema corporativo associava-se o saber das terras distantes, trazidos para casa pelos migrantes, com o saber do passado, recolhido pelo trabalhador sedentário (Benjamin 1985b: 198-199).

A interpenetração desses dois saberes - tal como acontece nos ritos de passagem - requer a transformação do estranho em familiar, e, ao mesmo tempo, um movimento inverso capaz de provocar, em relação ao familiar, um efei- to de estranhamento. No relato benjaminiano, tanto a figura do sedentário como a do estrangeiro produzem estranhamento: uma, no caso do estrangeiro, suscitando distância espacial, e outra, no caso do sedentário, distância temporal. Através do saber recolhido pelo sedentário, o passado faz estremecer o presente.

Um detalhe chama atenção: a relaçáo entre o mestre sedentário e os aprendizes migrantes se constitui numa oficina de trabalho. Num ambiente como esse, ao mesmo tempo em que elementos extraordinários iluminam o cotidiano, este náo deixa de provocar os seus próprios efeitos de interrupção - sobre as teias do extraordinário. Esse detalhe, parece-me, pode ser significativo, iluminando algumas das margens do pensamento de Turner.

Mas, antes de lidar com essas ou outras margens, deve-se ressaltar uma segunda afinidade entre as visóes dos dois autores: a discussáo de Turner sobre o enfraquecimento da experiência de liminaridade no mundo contemporâneo ressoa nas análises benjaminianas sobre o declínio da grande tradição narrativa, e debilitação de uma experiência coletiva, comunicável, e tecida na passagem das geraçóes (erfahrung). Sabedoria, diz Benjamin, se expressa num conselho a respeito de como continuar uma história. Na medida em que as pessoas já náo passam pelas mesmas experiências, ou, se passando, não conseguem articular o presente ao que foi transmitido de geração em geraçáo - como no caso dos soldados que voltavam mudos da guerra -, a capacidade de dar conselhos entra em declínio. Resta-lhes a sua experiência vivida, erlebnis - e, diante da fragmentaçáo da experiência coletiva, a perplexidade em relação ao sentido de suas vidas.

Há, ainda, uma terceira afinidade. Ao deparar-se com as novas formas narrativas do cinema, da fotografia, etc., Benjamin encontra, em sua dimensão mais profunda, algo que evoca 
a grande tradição narrativa: o seu "náo-acabamento essencial” (Gagnebin 1985:12). Tratase da abertura dessa tradição para as múltiplas e espantosas possibilidades interpretativas. Como exemplo de narrativa tradicional, Benjamin apresenta a história de Psammenites, contada por Heródoto. E diz:

Heródoto não explica nada. Seu relato é dos mais secos. Por isso essa história do antigo Egito ainda é capaz, depois de milênios, de suscitar espanto e reflexão. Ela se assemelha a essas sementes de trigo que durante milhares de anos ficaram fechadas hermeticamente nas câmaras das pirâmides e que conservam até hoje suas forças germinativas (Benjamin 1985b: 204).

De modo semelhante, nos substratos mais fundos do entretenimento e dos novos gêneros de ação simbólica, Turner descobre as fontes do poder liminar. As formas expressivas que germinaram após a Revolução Industrial também propiciam manifestaçóes do caos criativo, capazes de surpreender, com efeitos de estranhamento, as configuraçóes do real, energizando e dando movência aos elementos do universo social e simbólico. Embora estejam às margens de processos centrais de reprodução da vida social, estas expressóes liminoides apresentam um potencial ainda maior do que as formas arcaicas para promover a transformação das relaçóes humanas.

\section{Margens das margens}

Antes de abandonar esta apresentação, arrisco algumas questóes:

1. O que dizer do ruído - a frase sobre "culturas declinantes" em que "o significado é de que não há significado" - provocado por Turner no momento em que o seu ensaio chega a um "final feliz"? Ressalta-se que o ruído ime- diatamente precede algumas de suas afirmaçóes mais entusiasmadas sobre communitas. ${ }^{16}$ Como interpretá-lo? Haveria aqui uma hesitação, e, quem sabe, um indício da cautela de Turner diante de manifestaçóes de communitas, particularmente em meio à fragmentação das relaçóes sociais e ao estilhaçamento do espelho mágico do ritual? ${ }^{17}$

2. Considerando-se que a experiência de communitas tende a irromper às margens $\mathrm{da}$ sociedade, o ruído produzido no texto de Turner seria proveniente de um duplo deslocamento - às margens das margens? ${ }^{18}$

16. "Um senso de harmonia com o universo se evidencia e o planeta inteiro é sentido como uma communitas" (Turner 1986: 43).

17. Tendo-se em vista o movimento de expansão do universo liminoide e seus efeitos de descentramento nas esferas de ação simbólica - evocativos, quem sabe, de uma espécie de revolução copernicana sob a égide do mercado -, haveria nas expressôes de nostalgia por liminaridade e communitas uma reação centrípeta, ou, ainda, uma tentação ptolomaica? Até que ponto a nostalgia pelo liminar manifesta processos de formação, num mercado do lazer, de centros de poder simbólico para controle e uso do "caos criativo" que se associa aos gêneros liminoides de expressão?

Em meio ao estilhaçamento, ressalta-se a perplexidade dos indivíduos. Mas, haveria como reviver as condiçôes do teatro antigo? O que implicaria "transferir o peso da responsabilidade de atribuição de significado do indivíduo para o grupo" (Turner 1986: 37)? Como reconstituir a coesão do universo simbólico em meio à proliferação das possibilidades interpretativas? E, nessas circunstâncias, como reviver experiências de communitas - sem que elas virem experiências coletivas em que "o significado é a falta de significado"? Enfim, uma questão de fundo: a constituição de centros gravitacionais num universo liminoide, e seus efeitos de atração sobre as margens.

18. O que irrompe às margens das margens? Turner compara uma experiência, no sentido que lhe é dado por Dilthey, a "uma pedra num jardim de areia Zen" (Turner 1986: 35). Quando pedras viram areia na órbita de uma reação centrípeta - em meio ao possível ofuscamento da visão - talvez seja preciso um duplo deslocamento do lugar olhado das coisas. Isso, para 
3. Se a experiência liminar caracteriza-se pelo efeito de estranhamento que se produz em relação ao cotidiano, este ruído pode sinalizar um estranhamento às avessas, provocado em relaçáo ao extraordinário ${ }^{19}$ Isso, a partir de um cotidiano estranhado? Não haveria aqui uma afinidade com ruídos produzidos em determinadas oficinas de trabalho, tais como as dos mestres sedentários e aprendizes migrantes discutidas por Benjamin, conforme vimos anteriormente?

4. Nas oficinas medievais, Benjamin se depara com a abertura da grande tradição narrativa para as múltiplas e espantosas possibilidades interpretativas. Se o modelo de drama social de Victor Turner, assim como o modelo de ritos de passagem de Van Gennep, nos leva a pensar em termos de uma oposição dialética entre dois momentos, o cotidiano e o extraordinário, o caso dessas oficinas não apresentaria um desafio metodológico, levando-nos a falar de um cotidiano extraordinário ou extraordinário cotidiano, que se configura num quase susto ou espanto diário? E de um espanto que se aloja numa tradição? Walter Benjamin escreve: "A tradição dos oprimidos nos ensina que o 'estado de exceção’ é a regra” (Benjamin 1985c: 226).

Ao tentar distinguir a sua abordagem da de Erving Goffman, Turner evoca, como vimos, uma distinçáo entre teatro e meta-teatro. Ao passo que Goffman toma interesse pelo teatro da vida cotidiana, Turner procura focar os momentos de interrupção, os instantes extraordinários, ou seja, o teatro desse teatro. Turner

descobrir elementos que se distinguem ou escapam inclusive da periferia carnavalizante do movimento ordenador - e para que o extraordinário não vire mera experiência.

19. Às margens das margens, abrem-se perspectivas num universo liminoide para que se possa detectar os efeitos de estranhamento que se produzem em relação não apenas ao cotidiano, mas ao extraordinário também. observa o meta-teatro da vida social. ${ }^{20}$ Mas, as oficinas descritas por Benjamin podem sugerir a necessidade de se juntar Goffman e Turner para tratar de um meta-teatro cotidiano. Afinal, espelhos mágicos também têm as suas oficinas. E viram estilhaços. Nas irrupçóes do extraordinário também se encontra a experiência do ordinário.

Enfim, de Dewey a Turner e de volta.

E uma pergunta de rodapé (virando texto): seriam determinadas manifestaçóes liminoides - com destaque aos ruídos que ocorrem às "margens das margens" dos processos centrais - mais fiéis, "em sua dimensão mais profunda”, ao legado da experiência liminar do que certas tentativas de reviver uma experiência de communitas em meio ao esfacelamento das relaçóes?21 Num mundo como esse, onde a experiência da fragmentação torna-se cotidiana, os efeitos de estranhamento e a percepção do inacabamento das coisas ganham densidade.

\section{Passagens}

Depois de haver brincado com "Dewey, Dilthey, and Drama...", sou tentado também a brincar com esta apresentação - que está prestes a desmanchar. Nesse caso, porém, intrigame ver como ela ilumina uma espécie de "rito

20. Cf. nota 11.

21. Estou parafraseando a frase de Jeanne Marie Gagnebin, que, numa análise do ensaio benjaminiano sobre "a obra de arte na era da reprodutibilidade técnica", escreve: "Essas tendências 'progressistas' da arte moderna, que reconstroem um universo incerto a partir de uma tradição esfacelada, são, em sua dimensão mais profunda, mais fiéis ao legado da grande tradição narrativa que as tentativas previamente condenadas de recriar o calor de uma experiência coletiva ('Erfahrung') a partir das experiências vividas isoladas ('Erlebnisse')". Ela completa: "Essa dimensão, que me parece fundamental na obra de Benjamin, é a da abertura" (Gagnebin 1985: 12; Benjamin 1985a: 165-196). 
de passagem" - aquém do drama. Tomando os três momentos dos "ritos de passagem" como elementos meta-narrativos (codificados "a", "b", e "c"), as seqüências da apresentação podem ser analisadas da seguinte forma:

[A] RITOS DE SEPARAÇÁO. PREPARANDO O LEITOR PARA O CONTATO COM UMA TRADUÇÁO. Após uma breve introduçáo, cujo intuito é de preparar o leitor para uma passagem, inicia-se num lugar relativamente familiar: os escritos de Victor Turner a respeito de ritos e dramas sociais. Aos poucos, como num "rito de separação", adentra-se em territórios menos conhecidos, apresentando ao leitor alguns dos estudos de Turner sobre a Antropologia da Performance e Antropologia da Experiência - lugar perigoso onde se localiza boa parte da obra não traduzida de Turner. Assim se prepara o leitor para o contato com uma tradução.

[B1] RITOS DE TRANSIÇÁO. BRINCANDO COM UMA META-NARRATIVA DO TEXTO TRADUZIDO. A seguir, como quem se encontra num "rito de transiçấo", brinca-se com o estranho, nele suscitando - um efeito de estranhamento. A brincadeira consiste em explorar o limen do texto traduzido de Turner. $\mathrm{O}$ próprio Turner (nosso "espírito ancestral") apresenta-se como um guia confiável, mostrando-nos como voltar ao lugar familiar de onde havíamos saído: os seus escritos sobre ritos e dramas sociais, e experiências de liminaridade e communitas.

[B2] RITOS DE TRANSIÇÁOO. BRINCANDO ÀS MARGENS DAS MARGENS. Porém, náo voltamos ao lugar familiar. A experiência de liminaridade ganha densidade. Náo apenas permanecemos em meio às discussóes do texto de Turner sobre a Antropologia da Experiência, mas, na companhia de Walter Benjamin (pessoa relativamente estranha à antropologia), exploramos os seus ruídos $\mathrm{e}$ margens. ${ }^{22}$ Quer dizer, vamos às margens das margens. Uma ressalva: esta liçáo aprendemos com o próprio Turner. O límen pode ser um lugar privilegiado para se observar um fenômeno, tal como um texto.

Enfim, esta apresentação revela características de um "rito de passagem". Falta-lhe, porém, o "rito de reagregaçáo" [C]. Trata-se de uma passagem para um estado - de passagem. No final, multiplicam-se as manifestaçóes de um gênero de discurso característico de "ritos de transiçáo": as perguntas sem respostas - boas para fazer pensar.

Traduçóes, como a que vem a seguir, são passagens. Requerem a transformação do estranho em familiar ao mesmo tempo em que provocam no familiar um efeito de estranhamento. Desenvolvem-se no límen. Este termo, como Turner gostava de lembrar, vem do latim antigo, que evoca o lugar de "surrar" e "debulhar". A idéia de extrair grãos ou sementes é sugestiva. No limen se encontram sementes que conservam as suas forças germinativas - tais como as dos relatos de Heródoto.

A imagem de uma oficina, que vimos discutindo nesta apresentação, também é interessante. $\mathrm{Na}$ oficina do tradutor interpenetram-se dois saberes, e duas línguas - uma que vem de longe, e outra supostamente sedentária. Ambas brincam com o perigo. $\mathrm{Na}$ entrada da oficina vem escrito: "tentar, aventurar-se, correr riscos".

\section{Referências bibliográficas}

ABRAHAMS, Roger D. 1986. "Ordinary and Extraordinary Experience". In TURNER, Victor e BRUNER, Edward M. (orgs.). The Anthropology of Experience. Urbana/Chicago: University of Illinois Press, pp. 45-72.

BARTHES, Roland. 1990. "Diderot, Brecht, Eisenstein". In O Óbvio e o Obtuso: Ensaios Críticos. Rio de Janeiro: Nova Fronteira, p. 85.

22. As aberturas para uma antropologia benjaminiana tornam-se expressivas nos estudos de Michael Taussig (Taussig 1980; 1986; 1993). 
BENJAMIN, Walter. 1985a. "A Obra de Arte na Era de Sua Reprodutibilidade Técnica”. In Obras Escolhidas: Magia e Técnica, Arte e Política. Volume 1. São Paulo: Editora Brasiliense.

. 1985b. “O Narrador”. In Obras Escolhidas: Magia e Técnica, Arte e Política. Volume 1. São Paulo: Editora Brasiliense.

. 1985c. "Sobre o Conceito de História". In BENJAMIN, Walter. Obras Escolhidas: Magia e Técnica, Arte e Política. Volume 1. São Paulo: Editora Brasiliense.

CLIFFORD, James, e MARCUS, George E. (orgs.). 1986. Writing Culture: The Poetics and Politics of Ethnography. Berkeley: University of California Press.

CSIKSZENTMIHALYI, Mihaly. 1990. Flow: The Psychology of Optimal Experience. New York: Haper \& Row Publishers.

DOUGLAS, Mary. [1966]. Pureza e Perigo. São Paulo: Perspectiva, 1976.

DURKHEIM, Émile. [1912]. As Formas Elementares da Vida Religiosa. São Paulo: Ediçōes Paulinas, 1989.

GAGNEBIN, Jeanne Marie. 1985. "Prefácio: Walter Benjamin ou a História Aberta". In BENJAMIN, Walter. Obras Escolhidas: Magia e Técnica, Arte e Politica. Volume 1. São Paulo: Editora Brasiliense.

1994. História e Narração em Walter Benjamin. São Paulo: Perspectiva.

GEERTZ, Clifford. [1980]. "Blurred Genres: The Refiguration of Social Thought”. In GEERTZ, Clifford. Local Knowledge: Further Essays in Interpretive Anthropology. New York: Basic Books, 1983.

GLUCKMAN, Max. 1954. Rituals of Rebellion in SouthEast Africa. Manchester: Manchester University Press. GOFFMAN, Erving. 1959. The Presentation of Self in Everyday Life. Garden City, New York: Doubleday Anchor Books.

MARCUS, George E., e FISCHER, Michael M. J. 1986. Anthropology as Cultural Critique: An Experimental Moment in the Human Sciences. Chicago: University of Chicago Press.

TAUSSIG, Michael. 1980. The Devil and Commodity Fetishism in South America. Chapel Hill: University of North Carolina Press.

1986. Shamanism, Colonialism, and the Wild Man: A Study in Terror and Healing. Chicago/ Londres: The University of Chicago Press.

. 1993. Mimesis and Alterity. New York/Londres: Routledge.

TURNER, Victor. [1957]. Schism and Continuity in an African Society: A Study of Ndembu Village Life. Oxford e Washington, D.C.: BERG, 1996. 1967a. "A Ndembu doctor in practice". In The Forest of Symbols: Aspects of Ndembu Ritual. Ithaca and London: Cornell University Press.

1967b. "Betwixt and Between: The Liminal Perido in Rites of Passage". In The Forest of Symbols: Aspects of Ndembu Ritual. Ithaca and London: Cornell University Press.

1968. The Drums of Affliction. London: Oxford University Press.

1969a. "Communitas: Model and Process". In The Ritual Process: Structure and Anti-Structure. Ithaca, New York: Cornell University Press, pp. 131-165.

1969b. "Liminality and Communitas". In The Ritual Process: Structure and Anti-Structure. Ithaca, New York: Cornell University Press.

1974a. "Hidalgo: History as Social Drama". In TURNER, Victor. Dramas, Fields and Metaphors: Symbolic Action in Human Society. Ithaca and London: Cornell University Press, pp. 98-155.

1974b. "Preface". In TURNER, Victor. Dramas, Fields and Metaphors: Symbolic Action in Human Society. Ithaca and London: Cornell University Press.

1974c. "Religious Paradigms and Political Action: Thomas Becket at the Council of Northhampton". In Dramas, Fields and Metaphors: Symbolic Action in Human Society. Ithaca and London: Cornell University Press, pp. 60-97.

1982a. From Ritual to Theatre: The Human Seriousness of Play. New York: PAJ Publications.

1982b. "Introduction". In TURNER, Victor. From Ritual to Theatre: The Human Seriousness of Play. New York: PAJ Publications.

1982c. "Liminal to Liminoid, in Play, Flow, Ritual: An Essay in Comparative Symbology". In TURNER, Victor. From Ritual to Theatre: The Human Seriousness of Play. New York: PAJ Publications.

1986. "Dewey, Dilthey, and Drama: An Essay in the Anthropology of Experience". In TURNER, Victor, e BRUNER, Edward M. (orgs). The Anthropology of Experience. Urbana e Chicago: University of Illinois Press.

1987a. "Images and Reflections: Ritual, Drama, Carnival, Film and Spectacle in Cultural Performance". In The Anthropology of Performance. New York: PAJ Publications.

1987b. "The Anthropology of Performance". In The Anthropology of Performance. New York: PAJ Publications.

VAN GENNEP, Arnold. [1908]. The Rites of Passage. Chicago: The University of Chicago Press, 1960. 